Working Paper 18/2009

10 December 2009

\title{
The Road to Recovery: Fiscal Stimulus, Financial SeCtor Rehabilitation, AND Potential Risks AHEad
}

\author{
Prepared by Zhiwei Zhang and Wenlang Zhang \\ Research Department
}

\begin{abstract}
The worst of the global financial crisis is probably behind us, but the trajectory to recovery may vary widely across economies. Employing a dynamic structural multi-country model with a financial accelerator, this paper studies the role of three important policy actions, fiscal stimulus, financial sector rehabilitation and exit from policy easing, behind economic recovery. The main finding is that while both fiscal stimulus and financial sector rehabilitation contribute to economic recovery, the former is likely to be less effective from a medium-term perspective and may generate some negative side effects. This finding suggests that policy priority (of advanced economies in particular) should be on continued financial sector rehabilitation. Moreover, international policy coordination is beneficial as it can generate non-negligible spillovers to regional economies. We also study a potential risk to economic recovery down the road. That is, the effects of overestimation of the post-crisis potential output by the monetary authorities in advanced economies in their policymaking. We find that this may affect economic recovery in the region through inflationary pressure and the consequent policy tightening.
\end{abstract}

JEL classification: G30, H50, H60

Keywords: GIMF model; Financial accelerator; Fiscal stimulus; Financial rehabilitation; Author's Email Address: zzhang@hkma.gov.hk; wzhang@hkma.gov.hk;

The views and analysis expressed in this paper are those of the authors, and do not necessarily represent the views of the Hong Kong Monetary Authority. 


\section{Executive Summary:}

- The worst of the financial crisis is probably behind us, but the trajectory to recovery may vary widely across economies. This paper explores the contributions of three important policy actions, fiscal stimulus, financial sector rehabilitation and exit from policy easing, to global economic recovery. To conduct the analysis, we adopt an extended version of the Global Integrated Monetary and Fiscal (GIMF) model which incorporates a financial accelerator.

- Both fiscal stimulus and financial sector rehabilitation are important for economic recovery in the short run, but their contributions differ widely across regions. The effectiveness of fiscal stimulus is found to be largely inversely related to the ratio of imports to GDP of an economy, with small open economies featuring lower fiscal spending multiplier. Financial sector rehabilitation seems to be more important for developed economies whose financial sectors were severely damaged in the crisis. Policy coordination between blocks is useful as it can generate some non-negligible positive spillovers to regional economies.

- Financial sector rehabilitation appears to be more effective from a medium-term perspective, as fundamental flaws in the current financial systems in advanced economies revealed by the crisis, if fully corrected, can persistently reduce funding costs, foster capital accumulation, and even fuel technology progress. In contrast, fiscal stimulus is mainly one-off and may generate some adverse side effects over the medium run due to concerns over fiscal sustainability and inflationary pressure. This suggests that policy priority, on the two sides of the Atlantic in particular, should be on financial reforms rather than on government spending.

- The deep crisis may have introduced a large degree of uncertainty in the potential output in the global economy, and makes it difficult for monetary authorities to calibrate the correct policy stance. If the monetary authorities in major economies underestimate the drop in potential output during the period of exit from conventional as well as unconventional policy actions taken earlier to fight the crisis, their policy stance could be overly accommodative and lead to global inflation and subsequent policy tightening. We simulate such a scenario for the US and find that the Asia-Pacific economies would be affected negatively, suffering an annual drop in output ranging from 0.5-0.8\% in the medium term. 


\section{INTRODUCTION}

The worst of the financial crisis is probably behind us, but the trajectory to recovery can vary widely across regions. This is because while some economies, advanced economies in particular, have been mainly hit on the financial fronts, others (emerging Asia for instance) have suffered most from the downturn in external demand. As the severely damaged balance sheets of both households and banks in major economies are unlikely to be fully repaired in a short period of time, the economic recovery could take a long time (IMF 2009c). ${ }^{1} \quad$ This paper explores the role of two driving forces behind the recovery across regions - fiscal stimulus and financial sector rehabilitation, and studies the implications of overestimation of potential output by monetary authorities in major economies during the period of exit from the policy easing introduced earlier. While the role of fiscal stimulus and financial rehabilitation is obviously important for understanding the recovery process, the risk of overestimating potential output in major developed economies has caught less attention. Given the strong financial and trade linkages between East Asia and the rest of the world, we illustrate how such risk could affect the region. We adopt an extended version of the Global Integrated Monetary and Fiscal Model (GIMF) that is built upon the idea of the "financial accelerator" to conduct the analysis (Bernanke et al. 1996). The incorporation of financial frictions is essential for analysing policy issues in financial crises.

We find both fiscal stimulus and financial sector rehabilitation can contribute significantly to the global economic recovery in the short run, but their effectiveness differs widely across regions. The impact of fiscal stimulus on output growth depends on the size of the package as well as on the fiscal spending multiplier. Our simulations indicate that the fiscal spending multiplier is largely inversely related to the ratio of imports to GDP of an economy. This is because a higher imports-to-GDP ratio implies that a larger portion of government expenditure has to be spent on imports, hence generating more significant leakage effects. In particular, Japan may feature a short-term fiscal spending multiplier of close to unity, whereas small open economies like Korea and Australia-New Zealand can see a multiplier of only around 0.75. Moreover, policy coordination between economies is beneficial as it can engender some significant positive spillovers. In particular, emerging Asia may benefit more in terms of output growth from global fiscal stimulus than advanced economies given its heavy dependence on the export sector. These findings are generally consistent with the literature on the effects of fiscal policy (Hemming, Mahfouz and Schimmelpfennig, 2002 and Baldacci et

\footnotetext{
Based on panel analysis, IMF (2009c) shows that financial crises may lead to a loss in short-run output of $3-5 \%$ and last for five to seven quarters on average, while other recessions may entail a loss in output of less than $4 \%$, with a duration of shorter than four quarters. Moreover, while it takes around six quarters for output to recover to its previous peak following a financial crisis, no more than four quarters is needed in other recessions.
} 
al. 2009). The direct effect of financial sector rehabilitation seems to be quite important for developed economies, and the spillover effect from the recovery of credit market conditions in these economies to emerging markets can be large. The reason why major economies may gain significantly from the relief of financial stress is that their financial sectors have been severely damaged during the crisis (Zhang et al. 2009).

From a medium-term perspective, however, fiscal stimulus can be less effective than financial sector rehabilitation. Moreover, large fiscal stimulus packages can generate some adverse side effects due to the concerns over fiscal sustainability and inflationary pressure. This suggests that financial sector rehabilitation, in the US and euro area in particular, rather than fiscal stimulus should be policy priority, supporting the call by the IMF for rebuilding health in financial sectors. These findings are consistent with the argument in academic literature and the lessons from past experiences that financial reforms are critical for a sustained recovery from banking crises (Koo and Kiser, 2001).

We also explore a risk facing the Asia-Pacific economies which arises from overestimation of post-crisis potential output by monetary authorities in major economies. If the drop in potential output is underestimated ${ }^{2}$, the policy stance could be overly accommodative and lead to global inflation and tightening. As a result, the prospect of economic recovery in the region would be affected. The recent debate between the Director of US National Economic Council Larry Summers and the CEO of PIMCO Mohamed El-Erian on the potential output in the US demonstrates the high relevance of this scenario (McKee 2009). We simulate such a scenario for the US and find that Asia-Pacific economies would be affected negatively through two channels: inflation spillover through surges in imports prices and interest rate spillover as emerging market bond rates would rise in response to higher bonds rates in developed economies. To be precise, the Asia-Pacific economies would suffer an annual drop in output ranging from $0.5-0.8 \%$ in the medium term.

The remainder of this paper is organised as follows. The second section makes a brief sketch of the extended GIMF model with a financial accelerator, which is the main tool used in the research below. Section III studies the effects of fiscal stimulus and financial sector stabilisation on output. Section IV discusses the impacts of the overestimation of potential output in the US on regional economies and Section V concludes the paper.

2 Based on the empirical evidence of 88 banking crises and 222 currency crises between the early 1970s and 2002, IMF (2009d) finds that banking crises may lead to a much larger decline in medium-term output than currency crises. 


\section{THE GIMF MODEL WITH FINANCIAL ACCELERATOR}

The GIMF is a multi-country dynamic stochastic general equilibrium (DSGE) model developed at the IMF and documented in Kumhof and Laxton (2009). The version with no financial accelerator has been used at the IMF in background papers during Article IV consultations, see IMF (2008) and Kumhof and Laxton (2007), for example. As will be illustrated below, this paper employs the extended version of the GIMF with financial accelerator which is useful for studying the current banking crisis. The model integrates domestic supply, demand, trade, and international asset markets in a single theoretical structure, thereby allowing transmission mechanisms to be fully articulated. Compared with conventional macro models, it as the following main features:

1. It has thirteen sectors that allow a more detailed exploration of the interaction between sectors and the transmission of shocks at sectoral levels than can be done with conventional macro models which usually divide an economy into three sectors (households, intermediate goods and final goods firms, and government).

2. There are wide-ranging nominal and real rigidities at the sectoral level generating realistic inertial dynamics for key macroeconomic variables. Moreover, these rigidities facilitate studying, among others, the impacts of structural reforms.

3. The GIMF is relatively flexible in capturing various forms of monetary policy. It uses an extended Taylor-type rule aimed mainly at stabilising inflation and output but can also consider various exchange rate regimes., such as flexible exchange rate, managed floating exchange rate or a fixed exchange rate systems. ${ }^{3}$

4. Unlike conventional DSGE models which are powerful in monetary policy analysis but weak in fiscal policy analysis due to the assumption of Ricardian households, the GIMF has a few key non-Ricardian features so that fiscal policy does matter in the short run as well as in the longer term. For instance, it assumes overlapping generation households which have age-dependent productivity. Therefore, changes in tax rates and government spending will affect households' consumption behaviour.

\footnotetext{
In the research below, we assume China implements a regime of managed floating exchange rate against the US dollar, and other economies a free floating exchange rate regime. Nevertheless, the exchange rate of China's currency becomes more flexible over time. To be precise, the coefficient of the bilateral exchange rate in the Taylor-type rule is set at 0.2 initially, and declines in the next few years gradually and reaches 0 in the tenth year.
} 
5. Last but not least, international trade can be well captured. Bilateral trade is disaggregated into intermediary goods and final goods, while final goods trade is further broken down into consumption and investment goods. In particular, raw materials, which account for a major part of trade for some economies, can be separated out from other intermediate goods. This setup allows the model to dissect the role played by trade patterns in the development of an economy. Two economies with similar openness but with different trade patterns and trade structure are likely to experience different effects when facing a common external shock.

The linkages between the thirteen sectors are briefly sketched below. Each economy is populated with two types of households, overlapping generations (OLG) households and liquidity constrained (LIQ) households. The main difference between these two types of households is that the latter do not have access to financial markets, and are forced to consume their after tax income each period. The OLG households enter financial markets through purchasing domestic government bonds and foreign bonds and making deposits at domestic banks. ${ }^{4}$ Unions buy labour services from the two types of households and sell them to intermediate goods manufacturers who also rent capital stock from entrepreneurs and then use the two factors to produce tradable and non-tradable goods. The intermediate goods are then sold to domestic distributors and import agents of foreign economies-this is the first layer of trade (intermediary goods trade). Distributors combine domestic and foreign-produced tradable goods with public infrastructure to produce output that will be used as inputs in the production of domestic consumption and investment goods on the one hand and exported on the other-this is the second layer of trade (final goods trade). Investment goods producers sell their final output to capital producers for the purpose of capital accumulation and to the government for the purpose of infrastructure investment. Capital producers buy old capital from and sell new capital stock to entrepreneurs who finance the amount of capital stock exceeding their net worth by loans from banks. Consumption goods producers sell their final output to the government and retailers, who in turn sell their output to households. A flowchart of the main sectors is shown in Figure 1.

Comparing the flowchart of the GIMF with no financial frictions in Zhang et al. (2009) with that in Figure 1 below, one can see that the extended version has three more sectors (capital producers, entrepreneurs and banks). The framework of financial frictions in the GIMF mainly follows that of Bernanke et al. (1996), illustrating to what extent the net worth of firms can affect their ability to get financing and more generally how financial frictions arising from asymmetric information between lenders and

4 Foreign bonds are assumed to be denominated in the US dollar in the research below. Banks are assumed to be perfectly competitive and make zero profits at equilibrium. 
borrowers may amplify the effects of an initial negative shock to the economy. ${ }^{5}$ To be precise, it is shown that firms have to pay an external financing premium (relative to the riskless rate) which is inversely related to their net worth when financial frictions exist. Given a common negative shock, real demand in the GIMF model with financial accelerator will contract more than that with no financial frictions. This is because in the model with no financial frictions firms can always get the optimal amount of funds and face no extra costs in addition to the riskless rate.

The extension of the GIMF model to an eight-region specification has been documented in N'Diaye et al. (2009). The eight blocks are the US, the euro area (EA), Japan, China, Korea, EMEAP6 (Hong Kong, Indonesia, Malaysia, the Philippines, Singapore, and Thailand) ${ }^{6}$, Australia and New Zealand (AU\&NZ, treated as one block because of their large commodity sector) and the rest of the world. It should be noted that economies lumped into one block are by no means homogenous. In fact, these economies differ significantly in monetary, exchange rate and fiscal policies, not to mention the relatively subtle differences in their economic structures. Theoretically, these economies could be represented individually in the model given the malleability of the GIMF. However, each block in the model is described with hundreds of parameters and equations, adding an extra block would require an enormous amount of resources for the calibration and simulation. The model is calibrated with actual data of 2006, with the details documented in N'Diaye et al. (2009). Given the above mentioned strengths of the GIMF, particularly its powerfulness in analysing issues in international economics and financial frictions, below we take it as the main instrument to study the impacts of fiscal stimulus and financial sector rehabilitation in the short run as well as in the medium term.

5 This is what the phrase of "financial accelerator" means.

6 The six economies are grouped together largely because of the similarity in their trade structure and their position in the vertical specialisation of production in the region. Capital goods account for about half of imports and exports of the EMEAP6 economies, while intermediary goods account for one fifth of their total trade. 
Figure 1: Flowchart of the GIMF Model with Financial Accelerator

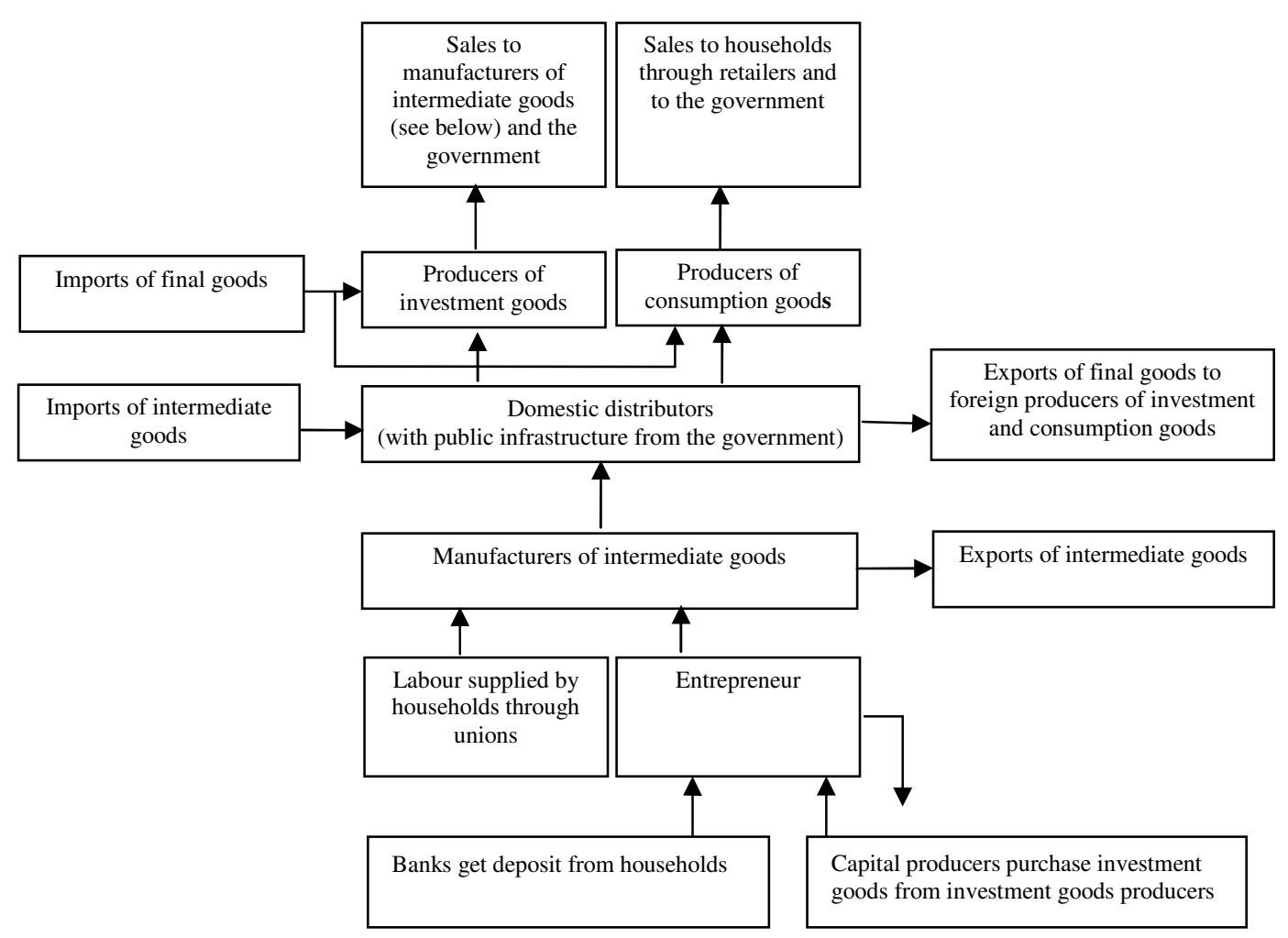

\section{How do Fiscal Stimulus and Financial Rehabilitation Help REGIONAL ECONOMIES RECOVER?}

\section{How much can fiscal stimulus contribute?}

In order to alleviate the adverse impact of the global financial crisis, policy makers in many economies have reacted by implementing fiscal stimulus to bolster domestic demand. This section explores how these fiscal impulses can help regional economies recover. The US government announced an impulse package of close to US $\$ 800$ billion, China released a package of RMB4 trillion for 2009-2010, ${ }^{7}$ and Japan, the euro area, Korea and other emerging Asian economies also took steps in a timely manner. The effectiveness of fiscal stimulus depends in large part upon the economic cyclical positions when it is launched, the composition of fiscal spending, and the openness of an economy (Hemming et al. 2002). In the scenarios below we simulate the cyclical conditions of this round of fiscal impulse with the actual year-on-year GDP contractions in the US, the euro area and Japan (G3) in 2008 Q3-2009 Q2. To consider the contagions to regional economies beyond trade channels we simulate the drops in asset prices in other economies accordingly. ${ }^{8}$ Regarding the composition of fiscal spending,

7 It is estimated that central government spending accounts for only about a third of the total package with the remaining coming from local governments and other sources.

8 Zhang et al. (2009) study how the US credit crisis spreads to other economies through financial channels in detail. 
in all blocks except Australia-New Zealand and China we assume that $70 \%$ of the government spending is allocated into investment and the remaining $30 \%$ in consumption, consistent with the statement of IMF (2009c) that around two-thirds of the fiscal stimulus in G-20 have been targeted at infrastructure. ${ }^{9}$ Our estimates indicate that in Australia-New Zealand about $30 \%$ of the stimulus is put in investment and the remaining $70 \%$ in consumption, whereas for China the distribution in investment and consumption is about $90 \%$ and $10 \%$ respectively (He et al. 2009).

Based on these assumptions, we introduce a shock to the ratio of government spending to GDP in each block according to the size of its respective fiscal stance in the fiscal year of 2008-2009 and find that the impact of fiscal stimulus differs widely across regions. The fiscal stance in percent of GDP of the US, euro area, Japan, China, EMEAP6, Korea and Australia-New Zealand is 2\%, 1.5\%, 2.6\%, 2.3\%, 2\%, 1.5\% and $2.0 \%$ respectively. ${ }^{10}$ To better understand the effectiveness of fiscal stimulus, we conduct the analysis in two steps. First, assuming that fiscal stimulus is implemented on an isolated basis in each economic block (i.e. only one economy to introduce fiscal stimulus at a time), we estimate the impacts of fiscal stimulus on individual economies' GDP in the first year as shown in Figure 2 (striped bars). In general, fiscal stimulus will raise output in all economies by over $1.0 \%$. In particular, the boost in Japan's GDP is estimated to be $2.5 \%$, thanks to its large fiscal stimulus package. In Figure 3 we show the short-run fiscal spending multiplier measured as the ratio of the increase in output in the first year to government spending across regions. The multiplier appears to be largely inversely related to the ratio of imports to GDP across blocks. This is because a larger portion of the stimulus package has to be spent on imports in economies which have a higher imports-to-GDP ratio. For example, Japan, which features the lowest ratio of imports to GDP in 2008 of around $15 \%$, has the highest multiplier of close to unity. In contrast, EMEAP6, which has the highest ratio of imports to GDP of around 75\% in the same year, features the lowest multiplier of close to 0.75 . This can also be confirmed by the changes in trade balance induced by fiscal impulses. While the ratio of trade balance to GDP in Japan declines by less than 0.4 percentage points, China, Korea and EMEAP6 may see a deterioration doubling that size. ${ }^{11}$ The multiplier can also tell us how much fiscal stimulus is needed if government spending is the only instrument to achieve a certain output growth rate in the short run. For instance, to raise the US GDP growth from $-2 \%$ to $2 \%$ requires a one-year fiscal stimulus of close to $5 \%$ of GDP with other things remaining unchanged.

9 We will also consider an alternative scenario assuming that half of the fiscal stimulus is allocated into government investment and the other half into government consumption.

10 Sources: IMF (2009c), People's Daily (2008) and authors' estimates. Fiscal stance refers to the negative of the cyclically adjusted fiscal balance. Note that for some economies the fiscal stimulus may last for more than one year, but we consider only one-year programs as the sizes of government spending in the second year in most economies are not yet clear.

11 A caveat is that initial fiscal stance may also affect the effectiveness of fiscal stimulus, as analyzed by Baldacci et al. (2009). IMF (2009d) also finds that the effectiveness of fiscal stimulus may decline with the government debt-to-GDP ratio, suggesting that the fiscal spending multipliers of economies which have already seen high government debt before the outbursts of the crisis (Japan, for example) may be lower than estimated here. 
The composition of the fiscal stimulus package may affect its effectiveness somewhat. To shed some light on this issue, we have conducted an alternative scenario assuming that half of government spending is allocated in investment and the other half in consumption. It is found that the multiplier may change by a magnitude of between 0.02 and 0.05 , with that of Japan, for example, shrinking from 0.96 in the original scenario to 0.92 in the alternative scenario. ${ }^{12}$

Policy coordination between economies can be beneficial since simultaneous fiscal stimulus may generate some positive spillovers from one block to another. As a second-step exercise, we assume that all economies implement fiscal stimulus simultaneously rather than on an isolated basis and present the spillover effects in Figure 4 (as measured by the differences between the solid and striped bars in Figure 2). It appears that Korea will benefit most from a positive spillover of over 0.9 percentage points of GDP growth, followed by China and EMEAP6. In contrast, the four advanced blocks of Japan, Australia-New Zealand, the US and the euro area are estimated to benefit less. The sizes of the spillovers largely reflect the relative importance of the export sector across these economies, thus suggesting that the improvement in external demand will likely play a more important role in prompting economic growth in emerging Asia than in developed regions. The fact that simultaneous fiscal stimuli can generate non-negligible synergy effects supports the call by the IMF for policy coordination to combat the worst global downturn in post-war history.

\section{Figure 2: Short-run Impacts of Fiscal Impulses on Regional GDP}

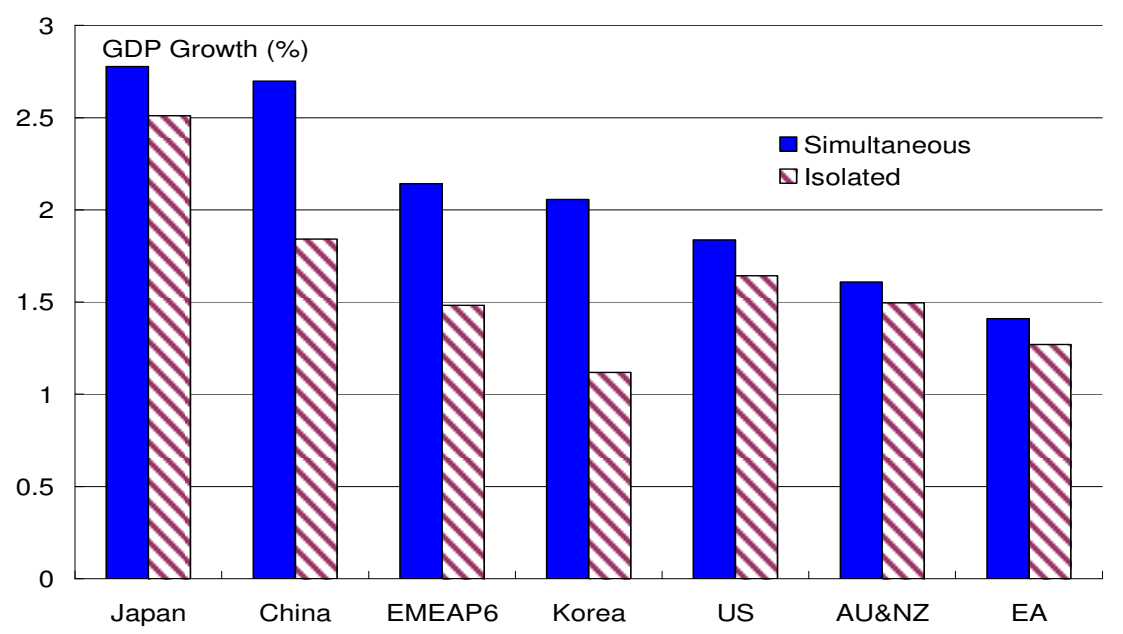

Source: authors' estimates.

${ }^{12}$ In the GIMF model a higher parameter is assigned to government investment than to government consumption in the public-private composite production function. Therefore, the more government spending distributed to government investment, the higher the multiplier, and vice versa. 
Figure 3: Short-run Government Spending Multiplier

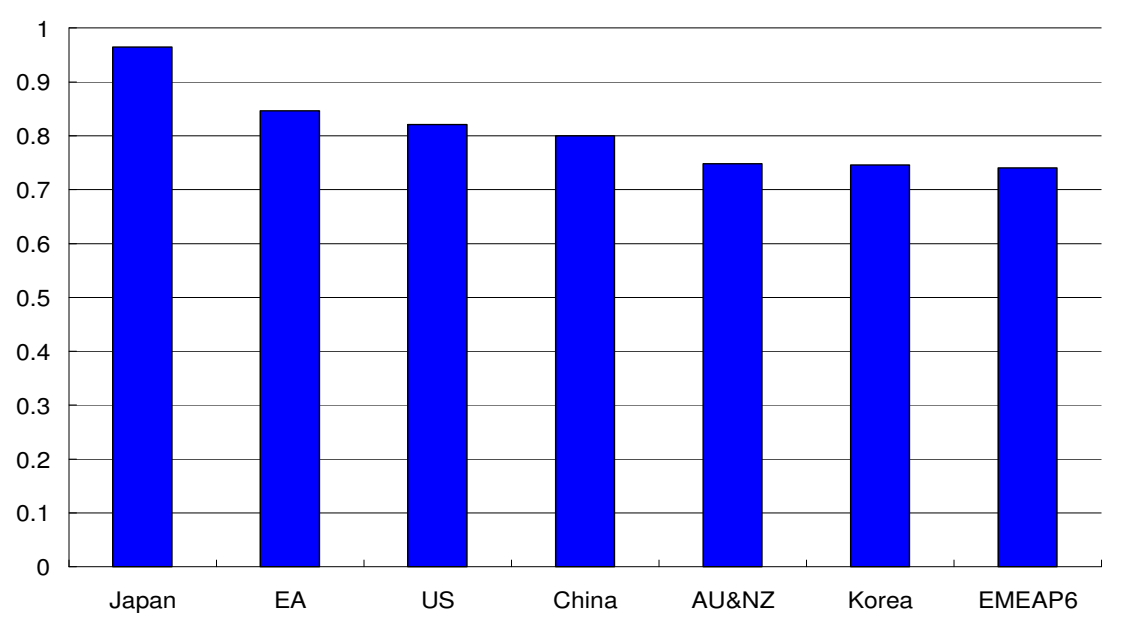

Source: authors' estimates.

Figure 4: Spillovers of Global Fiscal Stimulus

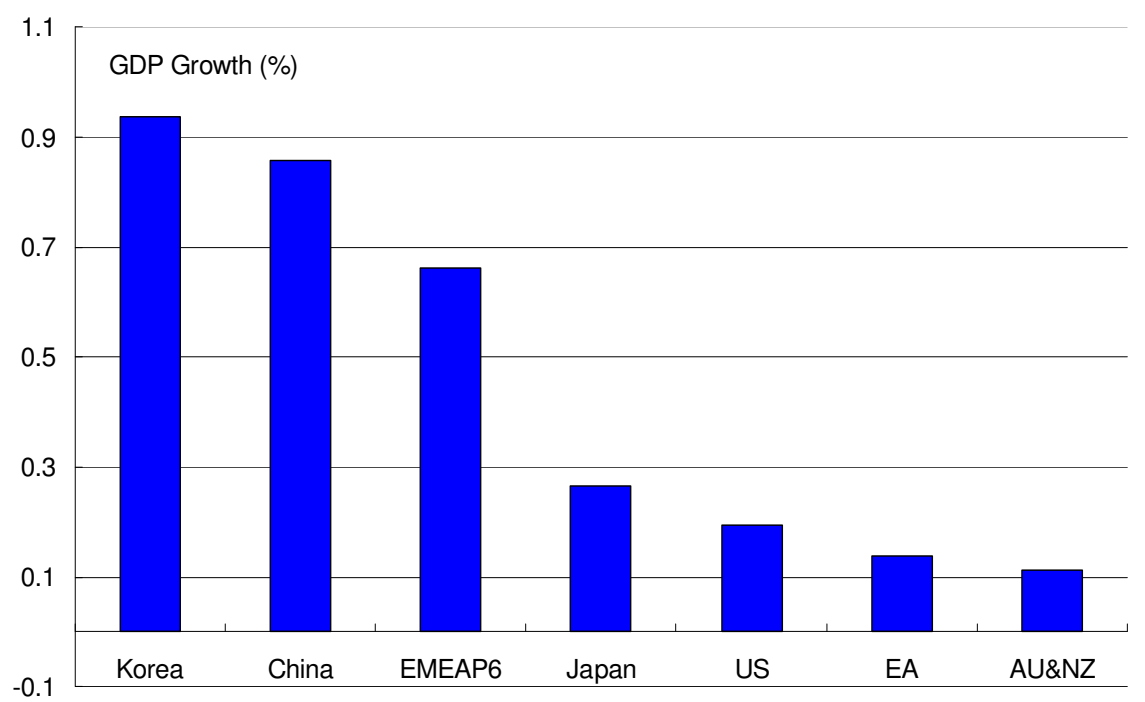

Source: authors' estimates.

\section{How much can financial rehabilitation contribute?}

The current financial crisis has been closely associated with the dysfunctions in the financial systems of the advanced economies, possibly suggesting that a sustained recovery can hardly be guaranteed unless the rehabilitation in financial sectors, in the US and the euro area in particular, takes root. This section studies to what extent rebuilding financial sectors' health can contribute to global recovery and how effective it will be when compared to fiscal stimulus. There have been heated discussions on how to realise financial rehabilitation. IMF (2009e), for instance, points out three priorities in this regard, namely ensuring financial institutions' access to liquidity, identifying and dealing with distressed assets, and recapitalising weak but viable institutions and resolving failed 
institutions. The US Department of Treasury has issued a handbook outlining the main points of financial regulatory reforms to prevent recurrence of banking crises. ${ }^{13}$ D'Arista and Griffith-Jones (2008) have also elaborated a few criteria and principles for financial regulatory reforms. ${ }^{14}$ Here we simulate the effects of financial rehabilitation by assuming that credit market conditions return to their pre-crisis state mainly due to successful financial reforms. That is, we assume credit spreads return to their average pre-crisis levels. As there is no credit spread in the GIMF model, we proxy it with the external financing premium which is measured as the ratio of aggregate monitoring costs to total loans.

Global credit conditions worsened noticeably during the crisis and did not show signs of improving until recently. As the balance sheets of the banks in the US were damaged by the deepening credit crisis, their counterparts in other regions also became more risk averse and strived to preserve capital amidst a worsening global economic outlook and tightened lending standards. Furthermore, as US banks became reluctant to lend US dollar to their counterparts in other economies, banks in those areas expanded their borrowings in non-dollar currencies and actively converted them into the US dollar through foreign-exchange swaps. This has also to some extent contributed to the tightening monetary conditions in the Asia-Pacific region. As a result, liquidity conditions deteriorated significantly despite accommodative monetary policies across the globe. In reality credit market conditions can be measured by the credit spread (CS), which is the difference between the yield of corporate bonds and sovereign bonds. As shown in Figure 5, it rose noticeably during 2008 Q4-2009 Q1. ${ }^{15}$ As conventional and unconventional policy measures including full deposit guarantees and enormous fiscal stimulus packages unfolded by authorities took effect, liquidity conditions started to improve in the second quarter of 2009, as evidenced by the continuous drops in the CS since April 2009. In the US, for example, the CS dropped from the peak of over 520 basis points in March to around 400 basis points in July, while that in the euro area also fell by more than 150 basis points during the same period.

13 "Financial Regulatory Reform. A New Foundation: Rebuilding Financial Supervision and Regulation". The reforms are aimed at five objectives: (1) Promoting robust supervision and regulation of financial firms, (2) establishing comprehensive regulation of financial markets, (3) protecting consumers and investors from financial abuse, (4) providing the government with tools it needs to manage financial crises, and (5) raising international regulatory standards and improving international cooperation.

14 (1) Regulation should be comprehensive, (2) asymmetries of information between markets and regulators should be reduced, (3) regulation should be counter-cyclical, (4) international coordination is important, and (5) compensation of bankers and fund mangers should be regulated.

15 The CS for small-and medium-sized enterprises (SMEs) was likely to be higher. IMF (2009b) shows that the lending to SMEs has declined more and faster than that to large firms in Korea over the past year. 


\section{Figure 5: Credit Spread across Regions}

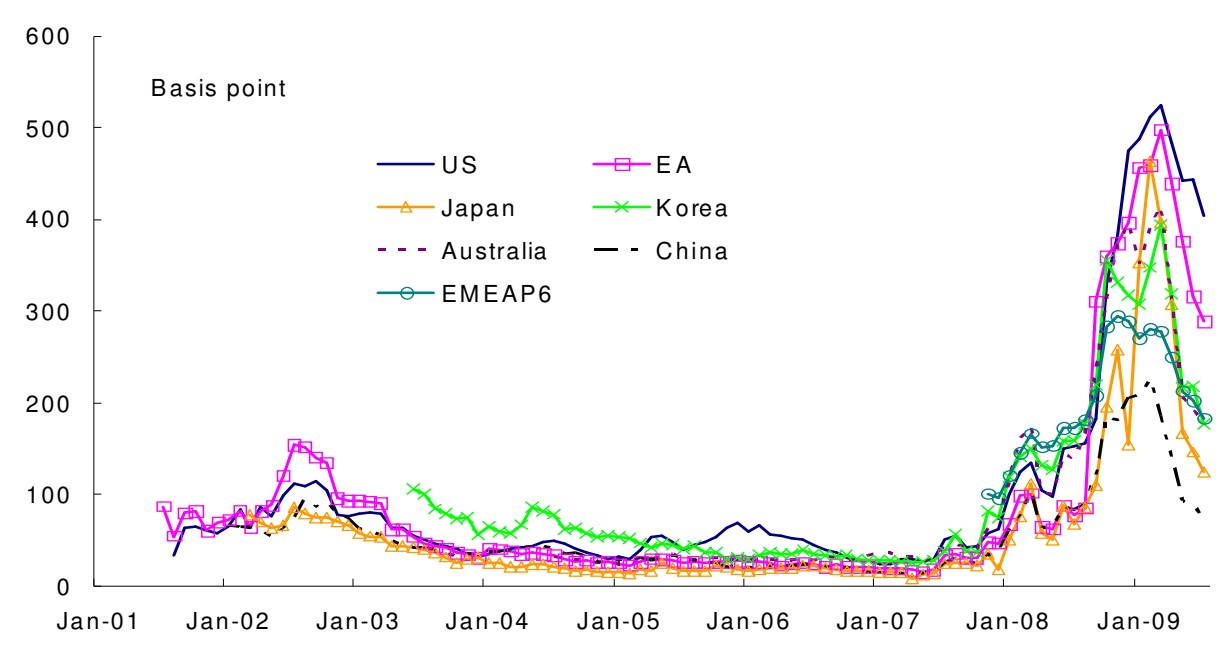

Note: This figure shows the average credit spread of samples from the top 50 corporations in each economy, with the number of samples differing across blocks. While 48 samples are considered for the euro area, 28 are considered for the US, for example. Sources: Bloomberg, Markit iTraxx Asia/Pacific and authors' estimates.

Our analysis shows that financial sector rehabilitation is important for recovery in economies which have been hurt severely on the financial fronts. Details of the exercises are given below. We shock entrepreneurs' riskiness such that the external financing premium in all regions drops by a magnitude in the line with the change in the credit spread. $^{16}$ The analysis is conducted in two steps. In the first step we assume that the external financing premium of each economy drops on an isolated basis. ${ }^{17}$ The impacts of reduced external financing premium on regional GDP in the first year are shown in Figure 6 (striped bars). Since the US and the euro area have originally suffered most from the dysfunction in financial markets, they are estimated to benefit more from financial sector rehabilitation than other regions. In particular, the US is estimated to see the largest rise in output by around $2.3 \%$, and the output of the euro area can gain by over $1.5 \%{ }^{18}$ In contrast, EMEAP6, China and Korea may benefit less, with output rising by

17 Entrepreneurs in the GIMF model differ with respect to net worth as well as productivity which is assumed to be subject to log normal distribution. Entrepreneurs with high enough productivity can repay their loans to banks and those with productivity below the threshold will go bankrupt and have to hand over all assets to banks. Here we reduce the riskiness of borrowers by shocking the standard deviation of entrepreneurs' productivity. The CS in the US, euro area, Japan, Australia-New Zealand, Korea, China, and EMEAP6 declines by around 390, 300, 250, 260, 250, 120 and 150 basis points, respectively.

18 One may argue that it is too optimistic to expect credit market conditions to return to their pre-crisis state as credit spreads before the crisis were extraordinarily low due to financial booming. Moreover, not all financial reforms will reduce credit spreads. If financial institutions are required to maintain a higher capital-to-loan ratio than the pre-crisis period, for example, credit spreads may also be higher than the average pre-crisis level. Therefore, we simulate an alternative scenario for the US assuming that its credit spread declines by around 300 basis points, almost 100 basis points less than in the above scenario, and find that GDP may grow by around $1.7 \%$ in the short run. 
about 0.6-1.0\%. Their relatively healthy banking sectors have prevented credit conditions from worsening as much as those on the two sides of the Atlantic, notwithstanding the fact that corporations in these economies are heavily reliant on banks for external financing, hence benefiting less from credit conditions returning to normal.

The second step of the exercise which assumes that financial sector rehabilitation takes place simultaneously across blocks indicates that international policy coordination can generate some non-negligible synergy effects. The solid bars in Figure 6 illustrate the changes in GDP in such a scenario. As expected, all economies will see larger rises in GDP, with the spillovers to individual economies shown in Figure $7 .{ }^{19}$ Emerging market economies may benefit more from spillovers given their large export sectors. This is consistent with what is observed in Figure 4, where global expansionary fiscal policy may also benefit emerging Asia more than other regions.

\section{Figure 6: Short-run Effects of Financial Rehabilitation}

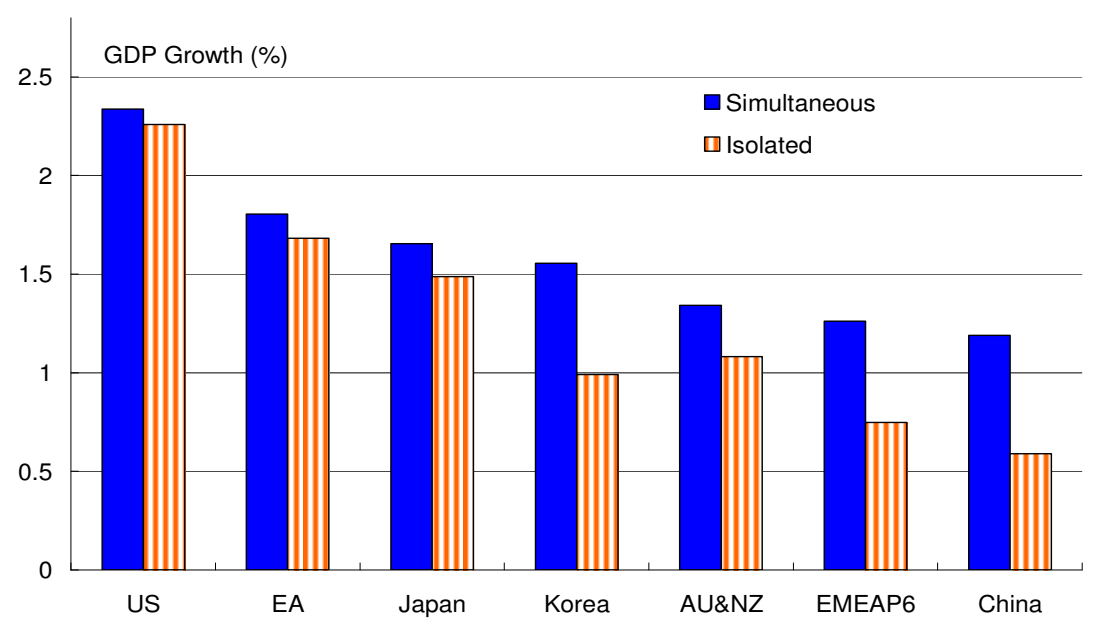

Source: authors' estimates.

19 In the GIMF model, the synergy effects of global financial rehabilitation mainly stem from the recovery in global demand due to declining funding costs. In reality, however, there may exist more channels through which international coordination can generate positive spillovers. In order to prevent possible regulatory arbitrage by moving activities to less regulated economies, for example, there have emerged calls for strengthening supervision on financial institutions across the globe to ensure financial stability. 


\section{Figure 7: Spillovers of Global Financial Sector Rehabilitation}

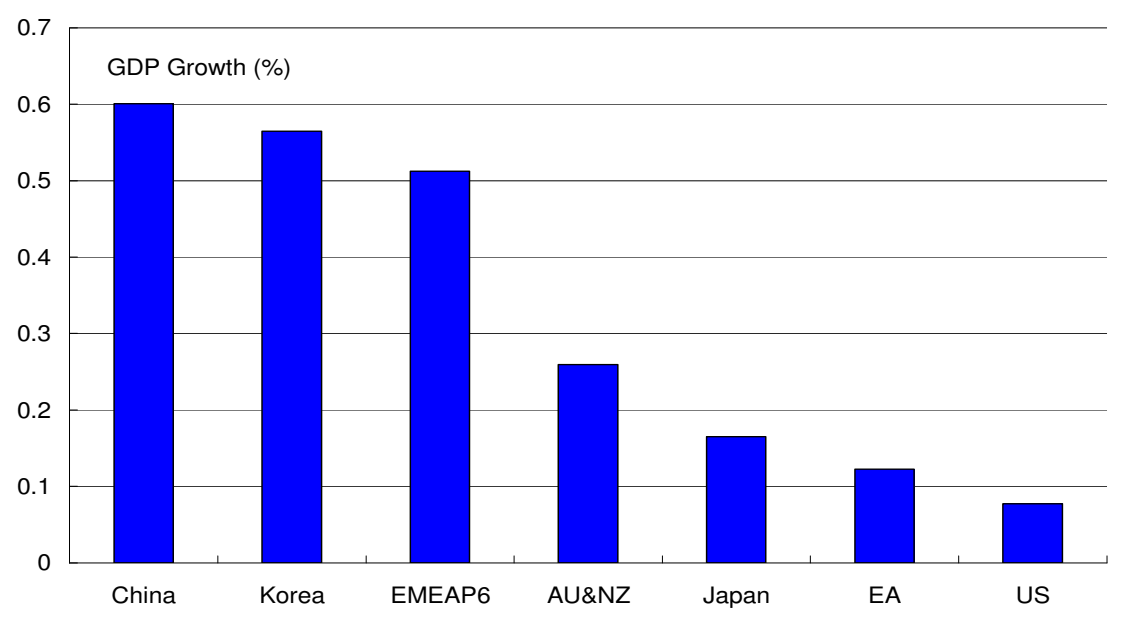

Source: authors' estimates.

The above analysis indicates that both fiscal stimulus and financial sector rehabilitation are important for recovery. In some economies government spending can even make a significant contribution to economic growth in the short run. For instance, Japan's fiscal stimulus can lead to a rise in GDP by $2.5 \%$, while financial sector rehabilitation can only drive up its short-run GDP by around 1.5\%. Nonetheless, as elaborated in IMF (2009a), the greatest policy priority for a sustained economic recovery is rebuilding health in the financial sector rather than increasing government expenditure. This is because fiscal stimulus, in comparison with financial sector rehabilitation, inherently features some weaknesses in tackling financial crises.

First, the effectiveness of fiscal stimulus is likely to wane rapidly, whereas financial sector rehabilitation can generate longer-term and more sustained effects. Figure 8 compares the medium-term GDP growth induced by fiscal stimulus and financial sector rehabilitation in the US and the euro area whose financial sectors have been badly damaged. The medium-term impacts of fiscal stimulus are smaller than those of financial rehabilitation. This can be attributable to two factors: (1) fiscal stimulus is one-off, whereas normalisation of credit market conditions can be persistent, and (2) while fiscal stimulus works mainly through the demand side of an economy, financial sector rehabilitation works in large part through the supply side by reducing funding costs, promoting capital accumulation, and hence fuelling technology progress. ${ }^{20}$ From a longer term perspective, it is the supply side, not the demand side, that creates growth.

${ }^{20}$ In addition to reducing firms' external financing premium, financial rehabilitation can also decrease firms' default probability. Our simulations show that the medium-term default probability in the US, euro area, Japan, Australia-New Zealand, Korea, EMEAP6 and China, can drop by 14, 6.8, 5.0, 6.1, 5.9, 5.0 and 2.6 percentage points, respectively. 
Secondly, the sharp rises in government debt induced by fiscal stimulus packages can trigger concerns over fiscal sustainability and inflationary pressure, and may cloud growth prospects. According to IMF (2009d), the ratio of fiscal balance to GDP in the advanced G-20 economies may worsen by six percentage points during 2008-2009 and by close to five percentage points in all G-20 economies as a whole over the same period. Meanwhile, the public debt-to-GDP ratio in these economies can worsen by over 14 percentage points and nine percentage points, respectively. In particular, the fiscal deficit-to-GDP ratio in the US can reach $12 \%$ in 2009 (in contrast with $2.9 \%$ in 2007), and exceed $7 \%$ in Japan (3.4\% in 2007) in the same year, with public debt in the two countries likely to register $100 \%$ and $222 \%$ of GDP in 2014 , respectively. ${ }^{21}$ As noted in IMF (2009a), although a significant rise in government debt is not inherently associated with major adverse implications for solvency, concerns over potential failure in fiscal consolidation, roll-over risks and the possibility of inflating away the debt can drive up long-term interest rates and pose threats to medium-term growth. These concerns usually turn out to be stronger for those economies which have already seen high pre-crisis government debt-to-GDP ratio, such as Greece and Italy.

\section{Figure 8: Medium-term Effects of Fiscal Stimulus and Financial Sector Rehabilitation}

USEuro

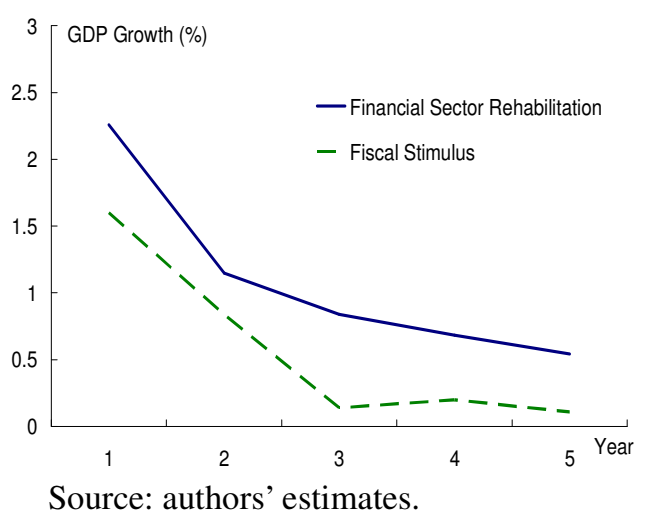

Area

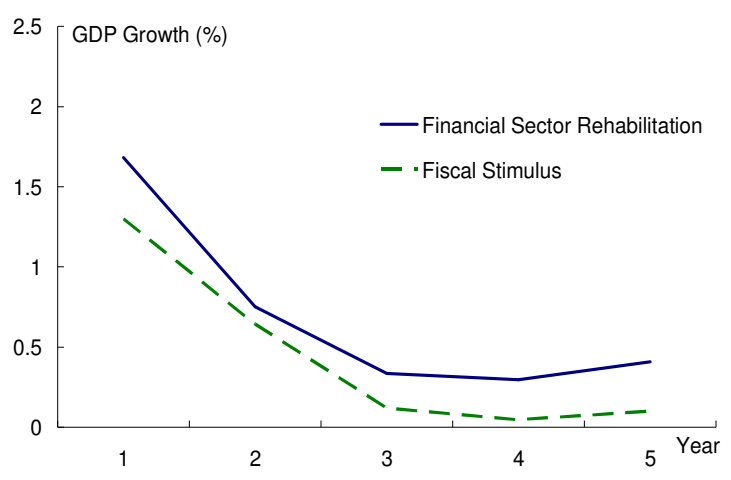

The main message from the analysis in this section is that both fiscal stimulus and financial sector rehabilitation are important in pulling global economy out of the recession, but the latter is set to generate longer-term and more sustained effects. Thus, policy priority on financial reforms, in particular on the two sides of the Atlantic will bear more fruitful outcome. ${ }^{22}$ At the same time, policy coordination between economies is also important since it can engender non-negligible synergy effects.

21 These projections are contingent upon the pace of global recovery. If growth in advanced economies declines by two percentage points during 2009-2013 relative to the baseline, fiscal balances in these economies would deteriorate on average by two percent of GDP, and the public debt-to-GDP ratio would rise by 18 percentage points.

22 In fact, the current recovery in credit market conditions has largely been driven by financial bailouts rather than by reforms in financial regulations. If the fundamental flaws in the financial systems of developed economies in particular, such as excessive risk-taking, can be fully corrected, the improvement in credit market conditions will likely be more sustainable. 


\section{How Can an Overestimation of Post-Crisis Potential OUtPut in THE US AFFECT EMEAP ECONOMIES?}

The road to recovery could also be affected by policy risks. The current financial crisis has created new challenges to the making of monetary policy, given the heightened uncertainty in potential output in the advanced economies. This section analyses the impacts on regional prospects of an overly loose monetary policy in the US arising from the authorities' overestimation of potential output over the period of the exit from the policy easing introduced earlier.

IMF (2009e) shows that the impacts of financial crises on medium-term output vary widely. Generally, there are three possibilities, with output (1) persistently growing at a rate lower than the pre-crisis period, (2) growing at a rate similar to the pre-crisis period, or (3) recovering quickly and growing at a pace faster than the pre-crisis period. As a result, potential output may (1) diverge further from the pre-crisis trend over time, (2) evolve at a level parallel to but lower than the old trend, or (3) return to or even outperform the previous trend. Given that many aspects of the current crisis are new and unanticipated, it is difficult to gauge the changes in potential output going forward. Based on the recent better-than-expected reading of data, authorities on both sides of the Atlantic seem to be tilted toward the view that the recovery may beat market expectations by coming more quickly than previously estimated. This points to the possibility that they may overstate the potential output over the years ahead. Against this backdrop, we analyse what would happen to growth and inflation in the region if policymakers in advanced economies overestimate potential output. To answer this question, one has to figure out first of all to what extent potential output may be overestimated. Based on the empirical evidence of OECD countries of 1960-2007, Furceri and Mourougane (2009) find that financial crises can pull down potential output by around 1.5-2.4\% on average, while a deep crisis can reduce potential output by close to $4 \%$. Based on such an assumption, the US potential output, if assumed to stay at the pre-crisis level, can be overestimated by $4 \% .^{23}$

Figure 9 illustrates the scenario graphically. The square-dotted curve stands for actual output, and the solid line is actual potential output which experiences a structural change and declines significantly in the aftermath of the crisis. The authorities do not realize the changes in potential output and mistake the dashed line as the new potential output. As a result, there is a four percentage-point difference between the actual output gap (actual output minus potential output) and that estimated by the authorities.

23 IMF (2009a) estimates that medium-term output can decline by around $8 \%$ relative to the pre-crisis trend in the fifth year following banking crises, four percentage points lower than the estimate of Furceri and Mourougane (2009). 
Figure 9: Actual and Estimated Potential Output

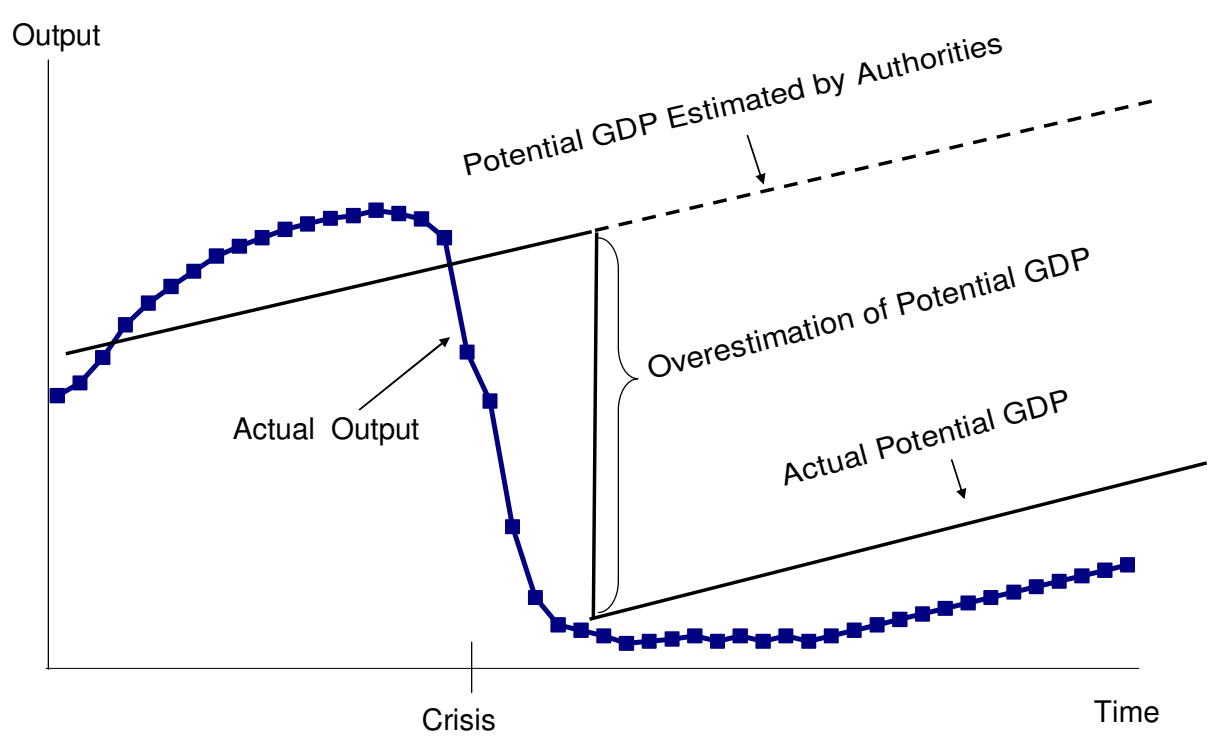

Overestimating potential output implies that monetary authority in the US will take an overly accommodative policy stance, which will lead to a resurgence in inflation. Rudebusch and Svensson (1999) estimate that a one percentage-point increase (decrease) in the US output gap may drive up (down) interest rate by 1-2.3 percentage points (around 1.1 percentage points on average) in the medium term. Furthermore, Berg et al. (2006) estimate that a one percentage-point rise (drop) in interest rate can drive down (up) inflation by over 0.5 percentage points. Thus, a four percentage-point drop in output gap may drive down interest rate by about four percentage points in the medium term, which will in turn push up inflation by over 2.2 percentage points. In the research below we assume that markets expect inflation to rise by 2.5 percentage points in the medium term due to an overestimation of the potential output, and study two cases that differ in the extent to which the US monetary policy reacts to inflationary pressure. In the first case we assume that the US monetary authority realizes the inflationary pressure and takes decisive actions to contain it. In this case we find that the negative spillovers to regional economies are tiny, as shown by the solid bars in Figure 10.

The second scenario assumes that the US authorities are unable to respond promptly to contain inflation, and as a result, inflation not only surges in the US but also spreads to other regions through, for example, surges in raw material prices and inflation expectation. This will lead to global inflation and hence monetary tightening in the other parts of the world. In such a scenario we find that inflation may eventually rise by $0.2-0.5$ percentage points in the Asia-Pacific region if policy makers in these economies react to inflationary pressure in a timely manner. Regional currencies may appreciate by around $5 \%$ against the US dollar in the fifth year after the shock, while output in these economies may see an annual drop of $0.1-0.55 \%$ on average over a period of five years (striped bars in Figure 10). 
Another channel through which a prolonged rise in inflation in the US can affect other economies is that markets may require a higher yield on sovereign bonds. Cheung et al. (2009) project the yield on the long-term US sovereign bonds (a proxy of equilibrium real interest rate) to rise by over 100 basis points in the next five years due to concerns over fiscal sustainability and inflationary pressure. Following their analysis, we assume a rise in the US equilibrium real interest rate of about 100 basis points. Meanwhile, equilibrium real interest rate in other economies is also assumed to rise in tandem, as the yield on long-term sovereign bonds in the US may serve as a benchmark for the yield on long-term sovereign bonds in these economies. ${ }^{24}$ The effects of higher global equilibrium real interest rate on regional GDP are represented by the checkered bars in Figure 10. Regional economies appear to be affected significantly, with Japan suffering the most, followed by EA, Korea and Australia-New Zealand. The aggregate impact (the checkered bars and the striped bars combined in Figure 10) of the overly loose US monetary policy then ranges from an average annual drop in GDP of $0.52 \%$ (AU\&NZ) to $0.84 \%$ (EMEAP6) in the medium term (five years).

Figure 10: Medium-term Impacts of an Overestimation of the US Potential Output

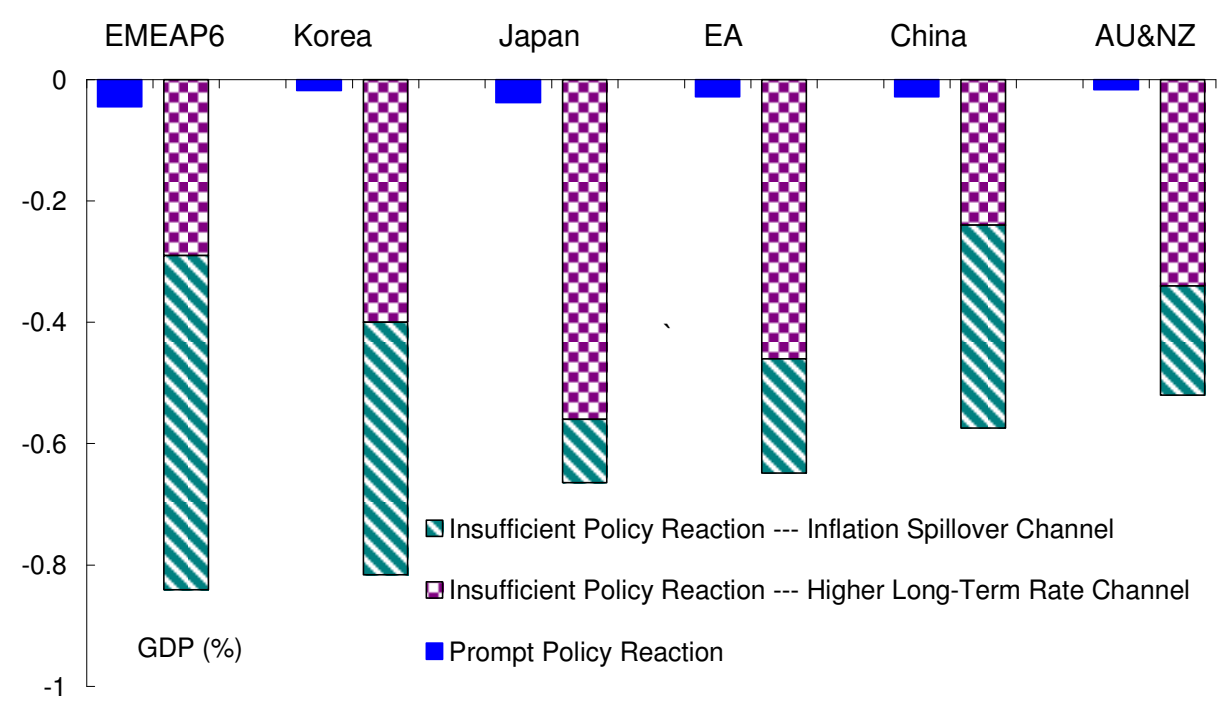

Note: This figure shows the impacts of the US inflationary pressure on regional output caused by an overestimation of potential output. The US inflation is simulated to rise by 2.5 percentage points in the medium term and dies out in the subsequent four to five years. Similarly, other regions' inflation of imports is simulated to rise by 2.5 percentage points over the same period and dies out gradually. Given that the openness of EMEAP6, Korea and China more than doubles that of other economies, we assume the imported inflation in these three blocks rises by around five percentage points over the same period. Source: authors' estimates.

${ }^{24}$ We shock the US equilibrium real interest rate by 100 basis points for five years and at the same time shock that of other economies according to the bilateral correlation between the US long-term bond yield and that of regional economies. The correlation coefficient between the US long-term sovereign bond yield and that of AU\&NZ, EMEAP6, China, EU, Japan and Korea is 0.86, 0.5, 0.1, 0.87, 0.87 and 0.5, respectively. The sample period to calculate the correlation differs across economies, ranging from the early 1970s (Australia) to early 2005 (Malaysia). The correlation coefficient for EMEAP6 is the average of the bilateral correlation coefficient between the US and the individual economies of EMEAP6. 


\section{CONCLUDING REMARKS}

Employing the extended GIMF model with a financial accelerator, this paper studies to what extent fiscal stimulus and financial sector rehabilitation can contribute to the global recovery. We also explore how overestimation of post-crisis potential output by policy makers may affect growth and inflation. The main findings can be summarised as follows:

- Both fiscal stimulus and financial sector rehabilitation are important for recovery, but the former is likely to be less effective from a medium-term perspective than the latter, and may generate some negative side effects due to the concerns over fiscal sustainability and inflationary pressure. This favours the call for continued financial sector reforms, in developed economies in particular.

- The fiscal spending multiplier is lower in small open economies than in advanced countries. Meanwhile, the relief of financial stress can play a more important role for the recovery of advanced economies which have been harder hit in the financial sectors than for emerging Asia which has suffered mainly from the worsening external conditions.

- International policy coordination is useful as it can engender non-negligible synergy effects. It has become increasingly important as the spillover of fiscal stimulus across countries is much larger in a globalised world with deepened trade linkages.

- The deep crisis may have caused a large degree of uncertainty in the potential output of the world economy, and makes calibrating the right monetary policy stance very difficult. Our simulations show that if the US authorities' overestimate the medium-term potential output, it can lead to global inflation and subsequent monetary tightening. This would generate noticeable repercussions on the prospect of recovery in the region. 


\section{REFERENCES}

Baldacci, E., S. Gupta and C. Mulas-Granados (2009), "How Effective is Fiscal Policy response in systemic banking crises?" IMF Working Paper 09/160.

Berg, A., P. Karam and D. Laxton (2006), "Practical Model-based Monetary Policy Analysis--- A how-to guide”, IMF Working Paper, WP/06/81.

Bernanke, B., M. Gertler, and S. Gilchrist (1996), "The Financial Accelerator and the Flight to Quality," The Review of Economics and Statistics, vol. 78(1), 1-15,

Cheung, L, C Tam, and J Szeto (2009), "Deteriorating Public Finance and Rising Government Debt: Implications for Monetary Policy", Hong Kong Monetary Authority Working Paper 15/2009.

D’Arista, J. and S. Griffith-Jones (2008), “Agenda and Criteria for Financial Regulatory Reform", manuscript.

David, E. P. and M. R. Stone (2004), "Corporate Financial Structure and Financial Stability", IMF Working Paper 04/124.

European Commission (2008), "Quarterly Report on the Euro Area", Volume 7, No. 4.

Furceri, D. and A. Mourougane (2009), "The Effect of Financial Crises on Potential Output: New Empirical Evidence from OECD Countries", OECD Economics Department Working Papers, No. 699.

He, D., Z. Zhang and W. Zhang (2009), "How large will be the effect of China's fiscal stimulus package on output and employment?" Pacific Economic Review 14 (5).

Hemming, R., S. Mahfouz and A. Schimmelpfennig (2002), "Fiscal policy and economic activity during recessions in advanced economies", IMF Working Paper 02/87.

International Monetary Fund (2008), "Japan: 2008 Article IV Consultation - Staff Report; Staff Statement; and Public Information Notice on the Executive Board Discussion.", Country Report No. 08/253.

International Monetary Fund (2009a), "World Economic Outlook”, October 2009.

International Monetary Fund (2009b), "The State of Public Finances: Outlook and Medium-term Policies after the 2008 Crisis”, Fiscal Affairs Department, March 6, 2009.

International Monetary Fund (2009c), "Regional Economic Outlook: Asia and Pacific", May 2009. 
International Monetary Fund (2009d), “World Economic Outlook”, May 2009.

International Monetary Fund (2009e), "Global Financial Stability Report---Responding to the Financial Crisis and Measuring Systemic Risk”, April 2009.

Koo, J. and S. L. Kiser (2001), "Recovery from a financial crisis: the case of South Korea", Economic And Financial Review Fourth Quarter 2001, Federal Reserve Bank of Dallas.

Kumhof, Michael and Douglas Laxton (2007), "A Party Without a Hangover? On the Effects of U.S. Government Deficits," IMF Working Paper, WP/07/202.

Kumhof, Michael and Douglas Laxton (2009), "The Global Integrated Monetary and Fiscal Model (GIMF) Technical Appendix," http://www.douglaslaxton.org.

McKee, M. (2009), "El-Erian 'New Normal' May Beat Summers 'Rocket Ship' This Week", Bloomberg news, October 122009.

N'Diaye, P., P. Zhang and W. Zhang (2009), "Structural Reform, Intra-regional Trade, and Medium-term Growth Prospects of East Asia and the Pacific---Perspectives from a new multi-region model", Journal of Asian Economics, in press.

People's Daily (2008), "Eurozone FMs Agree to Coordinate Fiscal Stimulus", 02 December, 2008, at http://english.peopledaily.com.cn.

Rudebusch, G. D. and L. E. Q. Svensson (1999), "Policy Rules for Inflation Targeting", in J. B. Taylor (ed.) Monetary Policy Rules, The University of Chicago Press: Chicago.

Zhang, W., Z. Zhang and G. Han (2009), "How does the US Credit Crisis Affect Asia-Pacific Economies? --- Analysis based on a general equilibrium model", Journal of Asian Economics (in press). 